European Journal of Personality

Eur. J. Pers. 13, 443-453 (1999)

\title{
Persons in Situations: Distinguishing New Wine from Old Wine in New Bottles
}

\author{
JOHN A. JOHNSON* \\ Pennsylvania State University, DuBois, USA
}

\begin{abstract}
An ambitious scientist dreams of overturning conventional wisdom and establishing a new paradigm that will provide a grand theoretical synthesis of the field. This commentary examines the articles of this special issue to distinguish what might be new from what is déjà vu to traditional, mainstream trait psychology. To accomplish this, the commentary begins with an exposition of how trait concepts are used in the natural sciences. This exposition is meant to correct a straw-man concept of traits, offered by some psychologists, as 'unmodulated consistencies in ... behavior across time and diverse situations' (Kenrick and Funder, 1988, p. 24). After presenting an accurate view of the trait concept, I examine what the authors of these articles offer as alternatives to traits, traditionally conceived. This examination shows that the authors occasionally misrepresent traits, and that in some cases their offered alternatives are actually quite similar to traditional trait conceptions. I end by describing what the traditional trait approach considers to be reasonable goals for personality psychology and the most promising methods for reaching those goals. Copyright (C) 1999 John Wiley \& Sons, Ltd.
\end{abstract}

\section{TRAITS AND SITUATIONS: LESSONS FROM THE NATURAL SCIENCES}

In its most generic sense, the term trait refers to any distinguishing characteristic, feature, property, or quality by which we identify something. More specifically, we have traits that refer to (a) physical appearance, (b) observable behavior patterns, and (c) inferred structural properties. For example, white and granular are traits that describe the physical appearance of both sodium chloride (table salt) and silicon dioxide (sand). Salt and sand show different behavior patterns in particular situations; salt is water-soluble whereas sand is non-water-soluble. Chemists explain what we observe about salt and sand in terms of their inferred atomic structures.

*Correspondence to: John A. Johnson, Penn State DuBois, College Place, DuBois, PA, USA. E-mail address: j5j@psu.edu

CCC 0890-2070/99/050443-11\$17.50

Copyright (C) 1999 John Wiley \& Sons, Ltd. 
Personality traits-just like the traits of physical substances-can refer to appearance, behavior, or structure. Only a few personality traits (e.g. ectomorphic), refer to physical appearance. More often, personality traits refer to dispositions toward manifesting observable behaviors (e.g. attention seeking) or to nonobservable, inferred characteristics (e.g. need for approval). We might therefore learn some lessons about personality traits by reflecting upon how traits and situations are conceptualized in the physical sciences.

The most important lesson we might learn from the natural sciences concerns the fallacy of the endlessly repeated assertion that 'Temporal stability and crosssituational consistency are considered prerequisites for the description of individuals in trait terms' (Steyer, Schmitt and Eid, 1999, p. 3). In reality, only temporal stability is crucial to the trait concept. Behavioral consistency across different situations is not. To determine whether a substance is weakly or strongly ferromagnetic, for example, we do not require it to show behavioral consistency across a wide variety of situations. What we require is replicable behavior (magnetic attraction and becoming magnetized) in the same type of situation (a magnetic field). This is temporal stability. Analogously, we can rightly attribute cooperativeness to a person who frequently (relative to some norm) shows the relevant behavior (compliance) in the relevant situation (reasonable requests) (Alston, 1975).

Mischel (1973) recognized that temporal stability — not consistency across different situations - is the hallmark of traits in the following passage: 'But the fact that behavior varies across different situations is not questioned by anyone, including classical trait theorists. More serious issues, instead, are the consistency-specificity with which the same person reacts to situations that ostensibly are relatively similar ...' (pp. 254-255, emphasis added). However, Mischel later downplayed temporal stability as something we all know and take for granted and redirected the personsituation debate back to the issue of cross-situational consistency (Mischel and Peake, 1982).

It is true that physical materials possess certain structural (as opposed to behavioral) traits that exist in any situation. A magnetized iron bar retains its alignment of atoms wherever it finds itself; consequently, magnetized is, in a sense, a 'cross-situationally consistent' property of that iron bar. But that structural property will result in predictable patterns of observable behavior only in relevant situations (e.g. the presence of electromagnetic fields or other ferromagnetic objects). Likewise, traditional personality trait psychologists assume that persons possess motivational structures (e.g. goals, needs, motives, and values) that endure across diverse situations but that activate observable behavior only under the right circumstances (see Alston's (1975) discussion of purposive-cognitive concepts). Likewise, Mischel (1979, p. 742) is interested in 'the pursuit of durable values and goals with stable skills and expectations for long periods of time'. Ultimately, for Allport (1937) and his followers, these enduring psychological structures exist because of enduring neurological structures.

Another lesson from the natural sciences concerns the speciousness of conceptualizing persons and situations as opposing forces whose relative powers can be compared. Water is often called 'the universal solvent' because many substances dissolve in water. So, in a trivial sense, an aqueous environment could be called a 'powerful' situation. But closer examination shows that the power of water to dissolve anything depends just as much on the structural properties of the substance as on the properties of water. Chemists do not debate whether the atomic structure of salt or 
water is the more 'powerful' force when salt dissolves in water. Thankfully, all of the articles in this special issue have heeded the good advice offered by Mischel (1973), 'It would be wasteful to create pseudo-controversies that pit person against situation in order to see which is more important' (pp. 255-256). Elsewhere (Johnson, 1999), I argue that attribution theorists' ill conceived efforts to compare persons and situations as competing forces reflect personal rather than scientific concerns.

\section{SITUATIONAL CONTEXT: OLD IDEA, NEW METHODS}

The articles in this special issue all agree that personality research should consider the situational context of behavior. Each article then offers a specific method for doing so. I applaud these methodological innovations. But I also want to note that considering the situational context of behavior is an old idea in trait psychology rather than a reconceptualization of traits. In the traditional conception of personality traits, every trait incorporates, whether explicitly or implicitly, a situational context that literally helps to define the trait. ${ }^{1}$ While it is true that isolated trait words such as cooperative contain no explicit reference to the relevant context (reasonable requests), the context is tacitly built in to the socially shared meaning of the trait word. The situation-boundness of traits applies equally to so called 'broad' or 'global' traits as well as 'narrow' traits. In Funder's (1991) words.

Every global trait is situation specific, in the sense that it is relevant to behavior in some (perhaps many), but not all, life situations. Sociability is relevant only to behavior in situations with other people present, aggressiveness when there is the potential for interpersonal confrontation, friendliness when positive interaction is possible, and so forth. Our intuitions handle this sort of situational delimitation routinely and easily (p. 36).

Recognizing that single trait words refer implicitly to situational contexts does not mean that we should allow contexts to remain implicit during personality assessment. I wholeheartedly endorse the suggestion of Van Mechelen and Kiers (1999) that, 'One may wish to go beyond decontextualized approaches to personality and move to studies of individual differences that include [explicit] references to specific contexts and specific behaviors' (p. 4). I also agree with the proposal of Ten Berge and De Raad (1999) to have respondents generate situations that help to define the personality traits we wish to assess. A respondent's view of the most relevant and prototypical situations (cf. Cantor, Mischel and Schwartz, 1982) for conceptualizing personality traits could be an interesting phenomenon in its own right, because understanding the tacit social rules underlying personality assessment is a form of social intelligence (Johnson, 1997a).

\footnotetext{
${ }^{1}$ The one exception to the rule that traits are defined by particular types of situation is the 'stylistic trait', which refers to how (i.e. in what manner) something is done rather than what is done. Alston (1975) offers methodical and energetic as examples of stylistic traits, for 'It would seem that one may proceed in a methodical or energetic manner in any situation in which one is doing anything' (p. 21). Hogan, Hogan and Roberts (1996) suggest that stylistic personality traits are more important than behavioral traits when it comes to effective job performance: '... it is not what a person does but how he or she does it (e.g. calmly, creatively, attentively, etc.) that determines effective performance' (p. 473).
} 


\section{THE CONDITIONAL 'IF-THEN' QUALITY OF TRAITS}

After reviewing the 'causal view' and 'summary view' of traits, which they claimed are both 'unconditional conceptualizations of dispositional constructs' (p. 1160), Wright and Mischel (1987) presented a conditional view of traits as 'an alternative conceptualization of dispositional constructs' (p. 1161). Following Wright and Mischel (1987), several of the articles in this special issue espouse this conditional or 'if-then' view of personality traits as a conceptual advance over traditional views of personality traits. But the conditional quality of traits is not a new alternative, it is actually part of the causal view of traits described 50 years ago by Ryle (1949) and discussed by Alston (1975) and Wiggins (1974, 1997). Wiggins presented Ryle's view of traits as causal dispositions as follows, 'According to the dispositional view, when we say that John is aggressive, we are asserting that it is a good bet that in certain circumstances, John will behave aggressively. ... The 'good bet' (Ryle's words) indicates that the subjunctive conditional is probabilistic in form' (p. 103). Ironically, proponents of the 'if-then' conception of traits have consistently rejected traits as causal, explanatory mechanisms (Mischel and Shoda, 1994) without realizing that Ryle's 'if-then' statements were meant to attribute causal properties to persons (Wiggins, 1974, 1997).

\section{ARE NARROWER TRAITS 'BETTER' THAN BROAD TRAITS?}

In his own analysis of personality traits, philosopher William Alston (1975) noted that Mischel (1968, 1973), although recognizing that broad traits have some utility, clearly favored narrow traits over broad traits and dynamic traits over descriptive traits. Several authors of articles in this special issue also seem to favor narrower traits. Do narrower traits in fact have any distinct advantages over broader traits?

The standard response to this question is to note the bandwidth/fidelity tradeoff (Cronbach and Gleser, 1957). This tradeoff says that, in theory, broad bandwidth ${ }^{2}$ traits are supposed to predict a wide range of criteria with modest accuracy (low fidelity), whilst narrow bandwidth traits are supposed to predict a more limited range of criteria with greater accuracy (high fidelity). The bandwidth/fidelity tradeoff is widely cited and accepted, particularly in personnel psychology (Buss, 1989; Hampson et al., 1986; Hogan et al., 1996). But is it really the case that the strongest associations are always between broad predictors and broad criteria and between narrow predictors and narrow criteria?

\footnotetext{
${ }^{2}$ Alston (1975) noted that behavioral traits can be broad or narrow in two senses (see also Moskowitz, 1982). First, trait breadth can refer to the number of distinct acts subsumed by the trait category. In this regard, Hampson, John and Goldberg (1986) and John, Hampson and Goldberg (1991) note that the category of potential warm or kind acts is broader than the category of charitable acts. Stated differently, there are more ways to be warm or kind than charitable. A second sense of trait breadth refers to the number of distinct, relevant situations subsumed by the trait category. For example, rule-abiding is as broad as the number of sets of rules one can identify; abiding by one's church's rules is a narrower trait. Hostile toward authority figures includes a potentially wide range of authority figures; hostile toward parents is a narrower trait.

The two senses of trait breadth are often mixed indiscriminately in discussions. Among the eight 'different situations' in the Carleton study (Shoda, 1999) we find three types of act subsumed by the conscientiousness category: neatness, punctuality and completion. Punctuality is broken down further into schoolwork punctuality (three assignments, two readings, and two study reports) and attendance punctuality (in a one-on-one situation - seven appointments - and in a group situation - four lectures). Completion refers to two assessments of readings completed and three assessments of percent of studies completed.
} 
Shoda (1999), in mathematically elegant fashion, shows that the bandwidth/fidelity tradeoff (although he does not recognize the phenomenon by that label) is slightly more complicated than most accounts indicate. Shoda demonstrates first that aggregate (i.e. broad bandwidth) predictors actually predict unaggregated (narrow bandwidth) criteria better than unaggregated (narrow) predictors if the criterion is not part of the aggregate predictor. On the other hand, if the criterion is part of the aggregate predictor, there is a tradeoff between reduced error variance and masked, situation-specific information. As person by situation interaction variance increases, aggregation (predictor breadth) becomes a liability rather than a boon, at which point narrow criteria are better predicted by narrow traits than broad traits. ${ }^{3}$

Shoda (1999) next demonstrates that the ability of an aggregate (broad bandwidth) predictor to predict an aggregate (broad bandwidth) criterion (based on components that do not overlap with the predictor's components) increases as the number of components within each aggregate increases. So, the traditional view that "broad best predicts broad' is true, and, in fact, the broader, the better. However, while presenting his novel insights with his excellent, mathematically parsimonious model, Shoda neglects to mention an important requirement: All components must be conceptually relevant to the same broad, superordinate personality trait (see Epstein, 1983, footnote 1). Adding components from irrelevant situations to increase breadth will not increase predictive accuracy. It seems to me that personality researchers too often fail to heed an admonition from Gardner Murphy (1967). Murphy warned that mathematics can lead us into 'various types of mysticism which become so fascinating, so enriching, and so sustaining that one finds it difficult indeed to come back to the world of plain things and the immediate world to be dealt with' (p. 428). Although I appreciate in particular the formal models in these articles that recapture meaningful variance from what was formerly considered error variance, I do worry about formalisms becoming the center of attention rather than a tool for representing personality concepts.

Shoda (1999), Van Mechelen and Kiers (1999), and Vansteelandt (1999) all suggest two further advantages for narrow traits over broad traits. First, they find that narrow traits provide more complete, differentiated information about individual persons. Second, they perceive narrow traits to provide a clearer route to personality dynamics. I shall next consider the alleged descriptive superiority of narrow traits and then examine the links to, and merits of, dynamic-trait conceptions of personality.

\section{PROFILE PATTERNS AND PERSON RELIABILITY}

One of Shoda's conclusions from his data analyses is that the average temporal stability of $r=0.275$ for the eight separate 'situations' masks differences in stability

\footnotetext{
${ }^{3}$ One might ask, in passing, 'Who wants to predict narrow criteria, particularly single acts?'. According to Hogan (1998), traditional personality measurement seeks only to predict significant, broad life outcomes such as vocational choices and job performance. 'Predicting these consequential outcomes should be contrasted with trying to predict a person's actions on a single occasion - whether you were early or late to work last Wednesday. That problem is intellectually uninteresting and a psychometric fool's errand' (p. 4). Elsewhere, he says, 'We rarely want to predict how late an employee will be next Tuesday; rather, we are interested in a person's punctuality. To predict punctuality - a broad bandwidth behavioral characteristic - we need constructs of the same bandwidth (i.e. personality dispositions)' (Hogan et al., 1996, p. 473).
} 
coefficients for these 'situations'. For example, one individual might show consistently extreme neatness over time, but an inconsistent record of completion, whereas another individual might show the opposite pattern. Shoda refers to the profile representing the relative stabilities of trait subcategories as a person's 'behavioral signature'.

One can hardly argue against the view that a set of scores for a person on narrow traits provides a more differentiated view of that person than an overall score on a superordinate trait. This is true by definition. But is Shoda's notion of a 'behavioral signature' a conceptual advance in personality assessment? Profiling in personality assessment, which dates back to the earliest multi-scale inventories, is certainly nothing new. Neither is profiling the subdomains of a broader trait domain, which is done routinely for inventories such as the NEO-PI-R (Costa and McCrae, 1995). Neither is the notion of assessing the reliability of an individual profile of scores (Jackson, 1976). Neither is computing the stability of profiles based on observer's assessment of single items; Block (1971) has done this using the California Q-set. Is there anything unique and progressive about Shoda's behavioral signatures?

The unique feature of the 'behavioral signature' as presented by Shoda (1999) may, unfortunately, be a weakening rather than an improvement over standard personality profiling. Each point in a standard personality profile represents an aggregate score. On self-report inventories these aggregates are built from responses to multiple items. Even for Q-set profiles, where each point represents one item, the items themselves are aggregate judgements of traits. In contrast, the points in the behavioral profiles offered by Shoda (1999) represent single behavioral acts. From the viewpoint of standard psychometrics, claiming that these profiles represent stable patterns of stability and instability to different situations is highly speculative. In an earlier article on behavioral profiling, Shoda, Mischel and Wright (1994) required a minimum of six observations per point in a profile. Even six observations may be too few to assess the tendency of a behavioral disposition to manifest itself in a particular situation. The following analogy between baseball batting averages and personality trait scores illustrates why this is so.

Baseball batting averages, like individuals' location on broad personality trait dimensions, summarize long-term trends in behavior over time and relevant situations (cf. Abelson, 1985). Just as broad personality trait scores can be split into narrower component trait scores, baseball averages can be decomposed into averages within different batting situations. For example, a baseball player who bats 0.350 (hits safely in 35 out of every 100 official at-bats) might hit 0.330 against left-handed pitchers and 0.370 against right-handed pitchers. Baseball statisticians routinely keep track of players' averages in a variety of batting situations, such as day versus night games, real versus artificial turf, and whether or not runners are in scoring position. If one wanted to compile very narrow, highly differentiated batting averages, one could calculate the averages for a combination of these situations, for example, a player's average against left-handed pitchers during day games on natural grass with a runner on third base. But, clearly, our faith in such a highly differentiated batting average depends on the number of observations we have for this specific situation.

My assessment, therefore, of the behavioral profiling of relatively narrow traits is that these profiles can indeed give us valuable, fine-grained portraits of individuals, but that the points in these profiles should be based on a sufficient number of observations before they can be reasonably interpreted. Current presentations of 
'behavioral profiling' worry me in that they sometimes represent a retrograde practice of defining personality consistency with pairs of isolated acts.

\section{THE BRIDGE FROM DESCRIPTIVE TO DYNAMIC TRAITS}

Van Mechelen and De Raad (1999) rightly note that synthetic, integrative thinking on the person-situation debate requires linking descriptive, dispositional traits to explanatory, dynamic traits. Shoda (1999), Van Mechelen and Kiers (1999), and Vansteelandt (1999) believe that this link is to be found between narrow traits and the Cognitive-Affective Personality System (CAPS; Mischel and Shoda, 1995, 1998) conception of personality dynamics. Like Weimer (1984), I appreciate and applaud any attempt to integrate descriptive and causal discourse in personality psychology. Nonetheless, I find that the current integrative efforts fall short of a unified theory for four reasons.

First, I see no compelling theoretical reasons why narrow traits should be closer than broad traits to explanatory, dynamic traits. In fact, Funder (1991) and McCrae and Costa (1995) describe senses in which broad (global) traits can be explanatory. Second, none of the current articles empirically demonstrates that variables in the CAPS model show stronger associations with narrow, situation-specific traits than with broad traits. Third, the current articles fail to recognize that ordinary trait terms often refer to underlying, dynamic traits as well as observable behavior traits (Johnson, 1997b). Thus, 'sociable' can refer to a need, desire, or longing for social contact or to a behavior pattern of frequent socializing. Conceivably, one could develop assessment instruments that measure either the dynamic or behavioral sense of a trait, although most existing scales probably confound the two. For example, in the article of Van Mechelen and Kiers (1999), the 'Values' items possibly measure some unknown combination of values per se plus patterns of valued behavior.

The fourth shortcoming of the present integrative efforts is with the CAPS model itself. Alston (1975, p. 29, footnote 2) points out that the variables in the CAPS model are precisely the types of concept used in perfectly ordinary, common-sense explanations of intentional actions. Common-sense explanations use desires, beliefs, and abilities to explain actions (Malle, 1999). In a common-sense explanation, an act is explained by suggesting that the actor (a) desired a certain goal, (b) believed that the action would help him/her reach the goal, and (c) had the ability to perform the act. At any point in time, a person has a number of desired goals that may conflict with each other and may possess several beliefs about alternative routes for reaching these goals. How a person actually behaves depends on the particular desires and beliefs that enter awareness and on relative strengths of various desires. Cheek and Buss (1981) show, for example, that the effect of sociability (in the dynamic sense of a preference or desire for social contact) on actual social behavior depends on another affective trait, shyness (feelings of tension, awkwardness, and discomfort around others).

One limitation of the CAPS model is its failure to advance our scientific understanding of personality dynamics beyond how we already understand human action from common sense. As far as I can tell, the labeling and re-labeling of desires, beliefs, and abilities has simply reflected the psychological jargon popular at that point in history (Funder, 1991, p. 31). CAPS originated (Mischel, 1973) as an $\mathrm{S} \rightarrow[\mathrm{O}] \rightarrow \mathrm{R}$ 
model advocated by social learning behaviorists in the 1960s, which explains the model's original label 'subjective-stimulus values' for desires. Likewise, 'stimulusoutcome expectancies' and 'behavior-outcome expectancies' reflect classical conditioning and operant condition terminology, respectively, for beliefs about the events expected to follow other events. Over time, the 'refinement' of the CAPS model has consisted of incorporating the psychological jargon du jour (e.g. cognitive heuristics, schemas, prototypes, efficacy, affects, goals). I am surprised and somewhat depressed about the enthusiasm for the CAPS model, but not because the model is wrong. The problem is that settling for this model indicates that we are content to merely re-label common sense concepts with jargon, as opposed to developing a truly scientific model of personality dynamics.

\section{PRIMROSE PATHS BETTER NOT TAKEN}

I would like to enter one final concern about the overriding research goals represented by following the CAPS model and narrowing our focus on increasingly specific situations. These practices indicate that 'predictions about the individual's probable behavior in specific situations' (Mischel, 1979, p. 743) is an attainable research goal. Like Hogan (1998), I think this goal is unrealistic. Here is why.

To know what an individual person will do on one occasion in a specific situation, a psychologist would have to have instantaneous access to the state of the person's mind across all of the activated cognitive-affective units (encodings, expectancies, goals, etc). This is because the immediate, proximal cause of behavior on a single occasion is, as Steyer et al. (1999) point out, the person's current state of mind. (Personality traits, in contrast, represent more remote, distal causes of behavior-McCrae and Costa, 1995.) I see no technology in any of these articles (or even on the horizon) for assessing an individual's psychological state at one point in time. The CAPS scale offered by Van Mechelen and Kiers (1999) assesses trait rather than state levels on the CAPS variables, and none of the mathematical manipulations in the other articles assess the state of individuals' minds. I think a more reasonable, achievable goal would be to develop better measures of traits as traditionally conceived (i.e. both descriptive and dynamic traits) to forecast broad patterns of the life course.

\section{REASONABLE GOALS AND PATHS FOR PERSONALITY PSYCHOLOGY}

Narrowing our focus toward specific behaviors on specific occasions seems to me the wrong direction for personality psychology. There is nothing inherently wrong in studying narrow traits, so long as adequate measurement reliability is achieved. Furthermore, making explicit the situational context for traits is a worthwhile goal. But narrow, limited domain approaches will not lead us to comprehensive, integrative models of personality. I conclude by suggesting what I regard as promising future directions for personality research.

For those so inclined, a widely accepted, comprehensive taxonomy of situations remains to be constructed. Ten Berge and De Raad (1999) review a number of proposed taxonomies, but none of these enjoys the level of acceptance of the FiveFactor Model of traits. Perhaps one of the problems is researchers' failure to use the 
same kind of descriptive unit for traits and situations. One exception, overlooked in the review of Ten Berge and De Raad is Holland's (1985) taxonomy of personality types and environments. By using the same language (e.g. artistic) to describe persons and environments, Holland's system embodies the insight that the most important feature of situations is the type of person found in that situation (Shoda, Mischel and Wright, 1993).

Another suggestion for movement toward a comprehensive model of personality is to focus primarily on traits that possess evolutionary significance for all of humankind (e.g. the disposition to experience jealousy-Buss, Larsen, Western and Semmelroth, 1992). Traits that reflect the specialized research interests of academic psychologists (e.g. ego control, need for cognition, hostile attribution style) may represent important scientific advances over the common sense traits found in natural languages. But because these technical constructs are inventions of scientific imagination, I wonder about their range of applicability in a comprehensive model of personality.

Finally, I think our discipline will make more progress when we understand that all forms of psychological assessment (even self-reports) represent social situations (Johnson, 1997a). A better understanding of the cognitive, motivational, and social dynamics of personality assessment will provide an important integration between the long-separated areas of personality theory and personality assessment.

\section{REFERENCES}

Abelson, R. P. (1985). 'A variance explanation paradox: when a little is a lot', Psychological Bulletin, 97: 129-133.

Allport, G. W. (1937). Personality: a Psychological Interpretation, Holt, New York.

Alston, W. P. (1975). 'Traits, consistency, and conceptual alternatives for personality theory', Journal for the Theory of Social Behaviour, 5: 17-48.

Block, J. (1971). Lives Through Time, Bancroft, Berkeley, CA.

Buss, A. H. (1989). 'Personality as traits', American Psychologist, 44: 1378-1388.

Buss, D. M., Larsen, R., Westen, D. and Semmelroth, J. (1992). 'Sex differences in jealousy: evolution, physiology, and psychology', Psychological Science, 3: 251-255.

Cantor, N., Mischel, W. and Schwartz, J. C. (1982). 'A prototype analysis of psychological situations', Cognitive Psychology, 14: 44-77.

Cheek, J. M. and Buss, A. H. (1981). 'Shyness and sociability', Journal of Personality and Social Psychology, 41: 330-339.

Costa, P. T. Jr. and McCrae, R. R. (1995). 'Domains and facets: hierarchical personality assessment using the revised NEO Personality Inventory', Journal of Personality Assessment, 64: $21-50$.

Cronbach, L. J. and Gleser, G. C. (1957). Psychological Tests and Personnel Decisions, University of Illinois, Urbana, IL.

Epstein, S. (1983). 'The stability of confusion: a reply to Mischel and Peake', Psychological Review, 90: 179-184.

Funder, D. C. (1991). 'Global traits: a neo-Allportian approach to personality', Psychological Science, 2: 31-39.

Hampson, S. E., John, O. P. and Goldberg, L. R. (1986). 'Category breadth and hierarchical structure in personality: studies of asymmetries in judgments of trait implications', Journal of Personality and Social Psychology, 51: 37-54.

Hogan, R. (1998). 'Reinventing personality', Journal of Social and Clinical Psychology, 17: $1-10$.

Hogan, R., Hogan, J. and Roberts, B. W. (1996). 'Personality measurement and employment decisions: questions and answers', American Psychologist, 51: 469-477. 
Holland, J. L. (1985). Making Vocational Choices: a Theory of Vocational Personalities and Work Environments 2nd edn, Prentice-Hall, Englewood Cliffs, NJ.

Jackson, D. N. (1976). 'The appraisal of personal reliability', paper presented at the meetings of the Society of Multivariate Experimental Psychology, University Park, PA, 1976.

John, O. P., Hampson, S. E. and Goldberg, L. R. (1991). 'The basic level in personality-trait hierarchies: studies of trait use and accessibility in different contexts', Journal of Personality and Social Psychology, 60: 348-361.

Johnson, J. A. (1997a). 'Seven social performance scales for the California Psychological Inventory', Human Performance, 10: 1-30.

Johnson, J. A. (1997b). 'Units of analysis for description and explanation in psychology'. In: Hogan, R., Johnson, J.A. and Briggs, S.R. (Eds), Handbook of Personality Psychology, pp. 73-93, Academic, San Diego, CA.

Johnson, J. A. (1999). 'Some hypotheses concerning attempts to separate situations from personality dispositions', paper presented at the 6th European Congress of Psychology, Rome, 1999.

Kenrick, D. T. and Funder, D. C. (1988). 'Profiting from controversy: lessons from the person-situation debate', American Psychologist, 43: 23-34.

Malle, B. F. (1999). 'How people explain behavior: a new theoretical framework', Personality and Social Psychology Review, 3: 1-26.

McCrae, R. R. and Costa, P. T. Jr. (1995). 'Trait explanations in personality psychology', European Journal of Personality, 9: 231-252.

Mischel, W. (1968). Personality and Assessment, Wiley, New York.

Mischel, W. (1973). 'Toward a cognitive social learning reconceptualization of personality', Psychological Review, 80: 252-283.

Mischel, W. (1979). 'On the interface of cognition and personality: beyond the personsituation debate', American Psychologist, 34: 740-754.

Mischel, W. and Peake, P. K. (1982). 'Beyond déjà vu in the search for cross-situational consistency', Psychological Review, 89: 730-755.

Mischel, W. and Shoda, Y. (1994). 'Personality psychology has two goals: must it be two fields?', Psychological Inquiry, 5: 156-158.

Mischel, W. and Shoda, Y. (1995). 'A cognitive-affective system theory of personality: reconceptualizing situations, dispositions, dynamics, and invariance in personality structure', Psychological Review, 102: 46-268.

Mischel, W. and Shoda, Y. (1998). 'Reconciling processing dynamics and personality dispositions', Annual Review of Psychology, 49: 229-258.

Moskowitz, D. S. (1982). 'Coherence and cross-situational generality in personality: a new analysis of old problems', Journal of Personality and Social Psychology, 43: 754-768.

Murphy, G. (1967). 'Pythagorean number theory and its implications for psychology', American Psychologist, 22: 423-431.

Ryle, G. (1949). The Concept of Mind, Barnes and Noble, New York.

Shoda, Y. (1999). 'A unified framework for the study of behavioral consistency: bridging person $\times$ situation interaction and the consistency paradox', European Journal of Personality, 13: 361-387.

Shoda, Y., Mischel, W. and Wright, J. C. (1993). 'Links between personality judgments and contextualized behavior patterns: situation-behavior profiles of personality prototypes', Social Cognition, 11: 399-429.

Shoda, Y., Mischel, W. and Wright, J. C. (1994). 'Intra-individual stability in the organization and patterning of behavior: incorporating psychological situations into the idiographic analysis of personality', Journal of Personality and Social Psychology, 67: 674-687.

Steyer, R., Schmitt, M. and Eid, M. (1999). 'Latent state-trait theory and research in personality and individual differences', European Journal of Personality, 13: 389-408.

Ten Berge, M. A. and De Raad, B. (1999). 'Taxonomies of situations from a trait psychological perspective. A review', European Journal of Personality, 13: 337-360.

Van Mechelen, I. and De Raad, B. (1999). 'Personality and situations: editorial', European Journal of Personality, 13: 333-336. 
Van Mechelen, I. and Kiers, H. A. L. (1999). 'Individual differences in anxiety responses to stressful situations: a three-mode component analysis model', European Journal of Personality, 13: 409-428.

Vansteelandt, K. (1999). 'A formal model for the competency-demand hypothesis', European Journal of Personality.

Weimer, W. B. (1984). 'Limitations of the dispositional analysis of behavior'. In: Royce, J.R. and Mos, L.P. (Eds), Annals of Theoretical Psychology, pp. 161-198, Plenum, New York.

Wiggins, J. S. (1997). 'In defense of traits'. In: Hogan, R., Johnson, J.A. and Briggs, S.R. (Eds), Handbook of Personality Psychology, pp. 95-115, Academic Press, San Diego, CA, Originally presented as an invited address to the 9th Annual Symposium on Recent Developments in the Use of the MMPI, Los Angeles, 1974.

Wright, J. C. and Mischel, W. (1987). 'A conditional approach to dispositional constructs: the local predictability of social behavior', Journal of Personality and Social Psychology, 53: $1159-1177$. 